\title{
Response of Growing Media and IBA Application under Different Weather Conditions on Growth of Pomegranate (Punica granatum L.) Cuttings
}

\author{
B. Avu. Durga ${ }^{1}$ and Jatinder Singh ${ }^{2 *}$ \\ ${ }^{1}$ Department of Horticulture, School of Agriculture, Lovely Professional University, \\ Punjab - 144001, India \\ ${ }^{2}$ Department of Fruit Science, Lovely Professional University, Phagwara, \\ Punjab - 144001, India \\ *Corresponding author
}

\section{Keywords}

Pomegranate, Cuttings, Growing media, IBA, and Weather

\section{Article Info}

Received:

12 October 2021

Accepted:

03 November 2021

Available Online:

10 November 2021
Pomegranate (Punica granatum L.) is an important commercial horticultural crop. The cultivation of this crop is increasing day by day. Mainly due to its survival nature, particularly in dry or less water available areas. Its propagation is possible by using seed but vegetative propagation methods are very popular. Even commercial propagation of pomegranate is done by cuttings. To fulfill the rising demand for highquality plant material, easy, fast, reliable, economical multiplications are required, and under such circumstances, cuttings are the best-suited material. This method of propagation can further be improved by the use of optimum growing media and application of various plant growth regulators Indole Butyric acid and its derivations. Moreover, the success of propagation depends on prevailing weather conditions and the time of planting. Perlite + vermiculite and a combination of vermiculite + coco peat in equal proportions, quick dip application of $2500 \mathrm{ppm} \mathrm{IBA}$, and planting in the spring season are considered ideal for fast and economical multiplication of pomegranate cuttings. Humid weather conditions during the spring season exhibit a good possibility of rooting and survival of the same. Therefore, the main aim of this review article is to collect/compile the information regarding the effect of growing media and applications of IBA under different weather regimes over previous years along with recent happenings.

\section{Introduction}

Pomegranate (Punica granatum L.) is a favourite table fruit of India. Globally it is recognized as a 'super-food' because of its nutritional value. Moreover, it has high economic and medicinal value. Its family is punicaceae and native to Iran (Persia). This fruit is well cultivated in arid and semi-arid conditions at $500 \mathrm{~m}$ above mean sea level. If 
irrigation facilities are available, pomegranate can survive well in dry, hot summer and cold winter also. In low winter temperature conditions, pomegranate trees are deciduous trees, while in tropical and subtropical areas, pomegranates behave like evergreen or partially deciduous trees. It becomes dormant for a significant period to tolerate frost conditions, but at $-11^{\circ} \mathrm{C}$ temperature, the trees show signs of injury. Pomegranate trees can be grown in drought-prone areas as it is fairly tolerant to drought. Also, pomegranate can be cultivated in calcareous and acidic soils. In the end, pomegranates can be grown in several agro climates, starting from tropical to temperate regions. Globally India is the largest producer of pomegranate while Iran ranks second. Generally, pomegranate trees grow best in a dry climate with mild winters that is why they are widely cultivated in drier areas of South Asia, The East Indies, Tropical Africa, Malaysia, and India. In India, pomegranate plantations can be found all over the country but it is cultivated commercially only in Maharashtra. Small scale plantations are also seen in Gujarat, Rajasthan, Karnataka, Tamil Nadu, Andhra Pradesh, Uttar Pradesh, Punjab, and Haryana. In India, the area under pomegranate plantations is 264 thousand hectares, with a production of 2329 thousand MT (NHB, 2020). Pomegranate can be propagated through sexual propagation like seed and other vegetative propagation methods i.e., suckers, cuttings, grafting, and layering, are also applicable. Conventionally, pomegranate plants are propagated from seeds but these are not used in commercial propagation due to certain reasons like variation and undesirable standards (Sonawane, 2017). Moreover, seed propagation is an easy and economical method of propagation but resultant seedlings are unsatisfactory. Plants produce uneven fruits and low yields. Seed propagation is done only for genetic programs, the production of disease-free plant material, and cryopreservation of germplasm (Taheri et al., 2014). The use of cuttings is the easiest and simplest method of propagation. Usually, 5-8 inch lengthy and $1 / 4^{\text {th }}$ inch diameter cuttings are used. Hardwood and semi-hardwood cuttings have high rooting capacity, so they are mainly used for commercial propagation. Singh (2017) reported that the rooting capacity of cuttings varies among different varieties and from place to place. It also depends on the season of planting and the age of the branch that is selected for cuttings making. Successful growing and rooting of cuttings require ideal growing media and PGR treatment under optimum weather conditions. The use of various suitable growing media can enhance the rooting of cuttings. Moreover, its growth and development are also affected by various factors like the condition of the mother plant, the season of planting, rain, irrigation, temperature, aftercare, etc. To promote the rooting process, plant growth regulators viz. auxins are used. Application of natural or synthetic auxin on cuttings is necessary to improve adventitious root initiation (Pacurar, 2014). Weather prevailing during the spring season offers a high possibility of rooting and survival of cuttings. Planting of cuttings is usually done in spring (February-March). But in subtropical regions planting in July and in tropical regions planting in August are ideal (NHB, 2020).

\section{Different growing media in agriculture and its importance}

For the successful propagation of cuttings, growing media plays a significant role. For this purpose selection of a suitable growing medium is a prime requisite. Ideal growing media provides physical strength (anchorage) to cuttings and maintains moisture content and permits the exchange of gases. It also provides nutrition for growth, metabolism, and development (Eed et al., 2015). The basic substrate of the growing media is soil. But in 
commercial propagation mostly soilless media like vermiculite, perlite, cocopeat, peat, and sand, etc. are used due to their particular properties as mentioned in table 2. Gurjar \& Patel (2007) planted hardwood cuttings in a mixture of sand + soil + leaf mold, rooting media and recorded improved results concerning root and shoot parameters. Ansari (2013) revealed that the choice of growing medium depends on availability, production cost, and the suitability of the planting material. He examined the interaction between collecting time of cuttings and media on rooting characteristics of pomegranate in cultivar Mala's torch and also studied the influence of different collection times of cuttings with an interval of fifteen days using different types of rooting media viz. perlite, cocopeat, vermiculite, sand, and equal mixes. The results revealed significant impacts of cutting preparation time including media used for planting on rooting characteristics. The most significant effects on rooting percentage and number of roots were recorded on, cuttings collected on $5^{\text {th }}$ Jan and $4^{\text {th }}$ Feb and planted in vermiculite followed by 19th Feb in vermiculite + sand. In another experiment, the maximum number of primary roots were noticed in vermiculite $(36.33 \%)$ and lowest in normal soil (16.67\%) (Rajkumar et al., 2019). Tanuja et al., (2017) recorded the best results in terms of high rooting percentage in the case of hardwood cuttings in vermiculite rooting media and low in the soil. Ansari (2013) carried an experiment on pomegranate cv. Malas torsh and noticed that cuttings treated with NAA 4000, grown in vermiculite + sand and vermiculite, showed improved results in terms of fresh weight and rooting percentage. In arid climatic conditions, Rajkumar et al., (2016) carried a research work on pomegranate cv. "Phule Arkata" and revealed that IBA@2500 ppm treated, grown in vermiculite showed better growth in terms of a higher number of roots and shoots per cutting, high fresh and dry weight of roots of cuttings but the maximum length of the root was noted in cuttings that were grown in sand + perlite media.

Kumar et al., (2017) experimented on pomegranate cv. Phule Arakta cuttings with various growing media and revealed the effect of each growing media and their combinations by noticing the rooting and shooting parameters (i.e., rooting percentage, no. roots per cutting, and length of the root), survival percentage, fresh and dry weight (table -1).

On this basis, the best results were offered by perlite + vermiculite $1: 1 \quad(\mathrm{v} / \mathrm{v})$ medium followed by vermiculite + coco peat in 1:1 $(\mathrm{v} / \mathrm{v})$ medium while perlite + vermiculite $1: 1$ $(\mathrm{v} / \mathrm{v})$ medium was considered favorable to high rate of rooting and better root and shoot development.

Manila et al., (2017) experimented on pomegranate cv. Kandhari hardwood cuttings with different growing media and concluded that cuttings grown in vermiculite displayed improved results concerning rooting parameters and cuttings grown in vermiculite and soil + vermiculite led to the maximum dry weight of roots. In another experiment by Kumar et al., (2017) on pomegranate cv. Phule Arakta with various growing media has done and revealed that the rooting media combination, perlite + vermiculite 1:1 (v/v), and vermiculite + coco peat promoted survival percentage, shoot, and root parameters. Research work conducted by Rathwa et al., (2017) on cv. Bhagwa (pomegranate) to evaluate the growth of cuttings with different growing media, found that hardwood cuttings in red soil + vermicompost (1:1) growing media showed maximum vegetative growth followed by red soil + city compost (1:1).

Ghani et al., (2019) treated cuttings of pomegranate with IBA treatment $(2500 \mathrm{ppm})$ by a quick dip method (for $5 \mathrm{sec}$.) and planted 
in 5 different growing media viz. sand, vermiculite, perlite, cocopeat, garden soil including control. They observed better responses in two cases viz. perlite + vermiculite $1: 1(\mathrm{v} / \mathrm{v})$ and vermiculite + coco peat $1: 1(\mathrm{v} / \mathrm{v})$ in terms of rooting percent (82.33), roots per cutting (32.67), fresh and dry weight of roots (0.61 and $2.08 \mathrm{mg}$ ) shoots per cutting (80.33) and survival (76.0\%).

It was concluded that this method may be considered as an appropriate possible alternative for the better rooting and establishment of pomegranate cv. Phule Arata. It was recommended that use of sand + soil + FYM (1:1:1) as a planting medium for cuttings cv. Phule Bhagwa. Pomegranate cuttings grown in soil + silt + vermicompost growing media showed the highest uptake of nitrogen and potassium while cuttings grown in media silt + vermicompost exhibited higher uptake of phosphorus (Deshmukh et al., 2019). It was noted that cuttings grown in soil + silt + vermicompost media showed the highest root parameters. Hardwood cuttings grow faster when grown in coco peat + sand (4:1) media under mist chamber conditions (Kumar et al., 2018).

Research work on cuttings of pomegranate cv. Super Baghwa with different combinations of propagating media under Chhattisgarh plains conditions, was carried out by Netam et al., (2020) and revealed that cuttings planted in sand + cocopeat (1:1) media performed well in terms of survival and rooting parameters.

Tanwar et al., (2020) conducted research work in Rajasthan to evaluate the influence of IBA concentration and rooting media on pomegranate hardwood cuttings of cultivar Bhagwa and explained that IBA@2000ppm treated cuttings planted in coco peat + perlite + vermiculite showed satisfactory results concerning survival and vegetative growth parameters. An experiment on pomegranate cuttings with various rooting media treatments conducted by Kumar et al., (2021) established that the rooting medium (Soil + Sand + Vermicompost) exhibited the most significant effect over other rooting media in respect of shoot and root parameters of stem cutting.

Cuttings of pomegranate cv. Bhagwa performed better when grown in soil + perlite (1:1) in terms of improved rooting. Cuttings that are grown in soil + sand + FYM (1:1:1) also performed well based on root parameters like length, fresh weight \& dry weight of rooted cuttings (Patel et al., 2020).

\section{PGR and its role in plant propagation}

Plant growth regulator, IBA (Indole 3- butyric acid) has been used extensively in agriculture for a long time to promote root growth of cuttings. It is a derivative of auxin having a role in root development aspects like regulating the size of the apical root meristem, development of lateral roots, and adventitious root formation (Frick et. al., 2018).

Singh, (2014) carried out a research trial (table 3 ) to assess the concentration of IBA suitable for improved cuttings growth under mist house conditions and concluded that $5 \mathrm{~g} . \mathrm{L}^{-1}$ IBA concentration treated cuttings led to better results than other treatments. The maximum growth of pomegranate cutting was recorded by Kumari (2014).

These cuttings were treated with 4000ppm IBA and grown in coir pith + FYM. Another study on 10 yrs old hardwood cuttings of pomegranate cv. Dholka with various concentrations of IBA and NAA was conducted by Panda et al., (2014) under Orissa coastal climatic conditions to find the best combination of IBA \& NAA on rooting of cuttings. 
Table.1 Various growing media effects on rooting parameters and survival percentage of Pomegranate (Punica granatum L.) cv. 'Phule Arkata' cuttings

\begin{tabular}{|c|c|c|c|c|}
\hline Growing media & $\begin{array}{c}\text { Root length } \\
\text { (cm) }\end{array}$ & $\begin{array}{c}\text { No. of roots per } \\
\text { cutting }\end{array}$ & $\begin{array}{c}\text { Rooting } \\
\text { percentage }\end{array}$ & $\begin{array}{c}\text { Survival } \\
\text { percentage }\end{array}$ \\
\hline Sand & 19.00 & 26.33 & 0.69 & 0.67 \\
\hline Perlite & 18.00 & 28.00 & 0.78 & 0.72 \\
\hline Vermiculite & 20.00 & 28.67 & 0.79 & 0.77 \\
\hline Coco peat & 21.00 & 29.00 & 0.72 & 0.67 \\
\hline Sand + Perlite & 22.33 & 29.67 & 0.75 & 0.73 \\
\hline Sand + Vermiculite & 23.67 & 33.00 & 0.79 & 0.77 \\
\hline Sand + Coco peat & 21.00 & 28.00 & 0.72 & 0.70 \\
\hline $\begin{array}{c}\text { Perlite + } \\
\text { Vermiculite }\end{array}$ & 23.00 & 32.67 & 0.82 & 0.76 \\
\hline Perlite + Coco peat & 23.67 & 32.67 & 0.78 & 0.79 \\
\hline $\begin{array}{c}\text { Vermiculite + Coco } \\
\text { peat }\end{array}$ & 22.00 & 30.00 & 0.81 & 0.60 \\
\hline Control (Garden & 17.00 & 24.67 & 0.62 & 72.64 \\
\hline soil) & & 29.33 & 75.33 & Kumar et al., (2017) \\
\hline General mean & 20.97 & & & \\
\hline
\end{tabular}

Table.2 Properties of different soilless growing media

\begin{tabular}{|c|c|c|}
\hline $\begin{array}{c}\text { S } \\
\text { No }\end{array}$ & $\begin{array}{l}\text { Growing } \\
\text { media }\end{array}$ & Properties \\
\hline 1 & Vermiculite & Lightweight and good absorbent of moisture. \\
\hline 2 & Perlite & Lightweight, porous, capillary action, and high-water holding capacity. \\
\hline 3 & Coco peat & $\begin{array}{c}\mathrm{EC}, \mathrm{pH} \text {, unique water holding capacity, acts against leaching and is good in } \\
\text { drainage. }\end{array}$ \\
\hline 4 & Sand & $\begin{array}{l}\text { Adhesiveness, porosity, promotes alkalinity, have a coarse texture, provide } \\
\text { good aeration, and improve the drainage system. }\end{array}$ \\
\hline 5 & Peat & Nutrients are restored and moisture is retained. \\
\hline 6 & $\begin{array}{l}\text { Sphagnum } \\
\text { moss }\end{array}$ & $\begin{array}{l}\text { Light in weight absorbs } 10 \text { to } 20 \text { times more water than its weight, inhibits } \\
\text { damping-off because it has fungicidal properties. }\end{array}$ \\
\hline 7 & Compost & $\begin{array}{l}\text { Fertilizer cum soil conditioner and acts as a natural pesticide due to presence } \\
\text { of humic acid or humus, porous in nature, provides nutrients, minerals and } \\
\text { supports vegetation. }\end{array}$ \\
\hline
\end{tabular}


Table.3 Effect of IBA concentrations on pomegranate (Punica granatum L.) cuttings.

\begin{tabular}{|c|c|c|c|c|c|c|c|c|c|c|c|c|}
\hline Treatments & $\begin{array}{l}\text { No. of } \\
\text { sprouted } \\
\text { cuttings }\end{array}$ & $\begin{array}{l}\text { No. of } \\
\text { sprouts } \\
\text { per } \\
\text { cutting }\end{array}$ & $\begin{array}{l}\text { No. of } \\
\text { Leaves }\end{array}$ & $\begin{array}{l}\text { Length } \\
\text { of } \\
\text { sprout }\end{array}$ & $\begin{array}{l}\text { (cm) } \\
\text { mber of } \\
\text { primary } \\
\text { roots }\end{array}$ & $\begin{array}{l}\text { Percentage } \\
\text { of rooted } \\
\text { cuttings }\end{array}$ & $\begin{array}{l}\text { Percentage } \\
\text { of } \\
\text { secondary } \\
\text { root }\end{array}$ & $\begin{array}{l}\text { Length } \\
\text { of root }\end{array}$ & $\begin{array}{c}(\mathbf{c m}) \\
\text { Diameter } \\
\text { of root }\end{array}$ & $\begin{array}{l}\text { Fresh } \\
\text { weight } \\
\text { of } \\
\operatorname{root}(g)\end{array}$ & $\begin{array}{l}\text { The } \\
\text { dry } \\
\text { weight } \\
\text { of } \\
\text { root(g) }\end{array}$ & $\begin{array}{c}\text { Diameter } \\
\text { of sprout } \\
(\mathbf{m m})\end{array}$ \\
\hline 1g.L-1 IBA & 5.33 & 5.00 & 22.67 & 15.52 & 25.85 & 53.33 & 66.66 & 16.30 & 1.11 & 0.94 & 0.48 & 2.17 \\
\hline 2g.L-1 IBA & 5.00 & 5.83 & 22.00 & 15.95 & 23.79 & 50.00 & 77.77 & 18.66 & 1.67 & 1.03 & 0.60 & 2.07 \\
\hline 3g.L-1 IBA & 5.67 & 6.00 & 18.33 & 17.00 & 22.11 & 56.67 & 88.89 & 24.63 & 2.00 & 1.33 & 0.78 & 2.83 \\
\hline 4g.L-1 IBA & 6.00 & 8.50 & 24.00 & 18.21 & 26.22 & 60.00 & 77.77 & 22.92 & 2.44 & 1.11 & 0.73 & 2.87 \\
\hline 5g.L-1 IBA & 7.33 & 9.20 & 25.33 & 20.53 & 29.26 & 73.33 & 100.00 & 24.88 & 3.11 & 1.61 & 1.13 & 3.00 \\
\hline Control & 4.33 & 4.67 & 11.67 & 9.36 & 16.89 & 43.33 & 44.44 & 13.06 & 1.00 & 0.65 & 0.29 & 1.00 \\
\hline $\mathrm{CD}$ at $5 \%$ & 1.39 & 0.99 & 7.03 & 2.05 & 5.19 & 13.95 & 30.64 & 5.66 & 0.63 & 0.37 & 0.32 & 0.60 \\
\hline
\end{tabular}


The results showed that cuttings treated with IBA@200ppm + NAA@200ppm performed better concerning rooting of cuttings but higher concentration (IBA@300ppm + NAA@300ppm) led to earlier growth of the root. To find the response of IBA on rooting of different genotypes of pomegranate cuttings Kahramanoglu et al., (2018) experimented in Turkey (subtropical climatic area).

They concluded that the 31-N-01 genotype showed better results when treated with IBA@1000ppm and also proved that a higher concentration of IBA performed well. Seiar (2016) experimented on cv. 'Bhagwat (pomegranate) in Kashmir and concluded that IBA 1500 ppm + NAA 1500 ppm gave better results regarding sprouting and rooting aspects. A combination of IBA 1500ppm + NAA 1000ppm also exhibited the best results concerning the highest sprout, the number of primary roots and secondary roots, fresh weight of sprout, dry weight of shoot, fresh weight of root, and the dry weight of root per cutting. Kaur et al., (2016) treated pomegranate cv. Ganesh cuttings with different concentrations of IBA and Phydroxybenzoic acid (PHB) to evaluate the best combination of IBA \& PHB and optimum planting time and found IBA 1000ppm + PHB $750 \mathrm{ppm}$ and planting time in August was found to be the most suitable.

Kaur et al., (2018) also concluded that IBA $1000 \mathrm{ppm}+$ PHB 750ppm yield the best results in promoting rooting and in vigorous growth of shoot in pomegranate cv. Ganesh cuttings. Research work was conducted by Kabir et al., (2017) in Bangladesh to evaluate the rooting ability of stem cuttings with the 3 different IBA concentrations under a non-mist propagator. It was concluded that $4000 \mathrm{ppm}$ IBA treated cuttings may be recommended for commercial propagation because they exhibited the highest survival and root diameter.
Pomegranate cuttings treated with IBA $1000 \mathrm{ppm}$ revealed the best performance in terms of vegetative parameters and the observation time was 90 and 120 days (Kamboj et al., 2017). Kumar et al., (2017) conducted a research experiment on hardwood cuttings of pomegranate cv. Ganesh evaluated the effect of different IBA doses on rooting, shooting and revealed that $500 \mathrm{ppm}$ IBA treated cuttings showed improved results. Hakim et al., (2018) treated cvs. Bhagwa and Ruby with two kinds of auxins (IBA \& NAA) and biofertilizers and concluded that treatment of IBA 1500 ppm + NAA 1500 ppm + Biomix showed the best results concerning total chlorophyll content of leaves and leaf area. Poudel et al., (2018) treated cuttings with $9000 \mathrm{ppm}$ and obtained better rooting than other treatments. It was concluded that 2000 ppm IBA $+1 \%$ Boric acid treatment led to the best results in respect of sprout and root parameters (Kumar et al., 2020). Bhagwa cuttings responded well with IBA@3000ppm treatment and cuttings treated with IBA@3000ppm \& grown in soil + perlite (1:1) led to the highest root growth (Patel et al., 2020). Rao et al., (2020) experimented with ten pomegranate cvs. with various IBA concentrations under Kashmir conditions and revealed that treatment of IBA@5000 ppm on pomegranate cvs. Kandhari Kabuli and Nabha resulted in better performance concerning the number of leaves, leaf area, and chlorophyll per cutting. Kumar et al., (2020) evaluated the combined effect of IBA and boric acid on pomegranate cuttings and results revealed that 2000 ppm IBA + Boric acid combination exhibited the highest vegetative growth of cuttings.

\section{Role of different weather conditions on propagation}

Pomegranate cuttings planted between $15^{\text {th }}$ December to $15^{\text {th }}$ January with a quick dip method (5 seconds) with IBA (Indole-3- 
butyric acid), led to good results on sprouting percentage (Singh et al., 2011). In another case cuttings planted in July, resulted in low sprouting of buds due to higher temperature (unfavourable for bud sprouting). These types of variations may also happen due to different species (Singh 2017). Cuttings had a better rooting percentage when taken at the end of February than at the beginning of October. The most important practice for cuttings is the time of stem selection. Based on the physiological potential rooting and shooting may perform well on cuttings (Chandra and Babu 2010). A research trial on pomegranate cv. 'Bhagwa' with various IBA and NAA concentrations in Kashmir, was carried out by Seiar (2016) to assess the growth of cuttings in temperate regions. Results showed that IBA $1500 \mathrm{ppm}+$ NAA 1500 ppm combination led to better results than other treatments concerning sprouting and rooting aspects. Another treatment viz. IBA 1500 ppm + PHB $1000 \mathrm{ppm}$ gave the best results regarding the highest sprout, the number of primary roots and secondary roots, fresh weight of sprout, dry weight of shoot, fresh weight of root, and the dry weight of root per cutting. Rajkumar et al., (2016) researched in the greenhouse under arid conditions to find the best concentration of IBA for root establishment and to evaluate growing media efficiency on pomegranate "Phule Arkata" cuttings and revealed that IBA@2500ppm treated cuttings gave satisfactory results in vermiculite regarding growth, establishment, and survival under an arid condition in the greenhouse. Under mist chamber conditions, July is considered the best planting time to get high-quality plant material (Kumar et al., 2018). Mehta et al., (2018) experimented on pomegranate cuttings with different concentrations of IBA and concluded that cuttings treated with 500 ppm IBA and planted in January, gave the best results. Hussain et al., (2019) conducted a trial with three different types of pomegranate cuttings i.e., softwood semi-hardwood, hardwood cuttings under three different environmental conditions i.e., shade house, plastic tunnel, and open field conditions.

These research results revealed that semihardwood cuttings exhibited the best results but it takes time to grow. In the case of environmental conditions, cuttings planted under plastic tunnels showed good results in the growth of cuttings while the lowest growth was recorded in open field conditions. Deshmukh et al., (2019) concluded that pomegranate cuttings planted on $15^{\text {th }}$ January showed higher uptake of nitrogen, potassium, phosphorus, etc.

An experiment on ten pomegranate varieties with various IBA concentrations was conducted in Kashmir (subtropical conditions) by Rao et al., (2020) and concluded that 5000 ppm of IBA, treated cuttings of cvs. Kandhari Kabuli and Nabha performed better in terms of leaf number, leaf area, and chlorophyll per cutting.

It has been proved that among various growing mediums perlite + vermiculite 1:1 $(\mathrm{v} / \mathrm{v})$ and vermiculite + coco peat are the bestgrowing media. IBA 5000 ppm had exhibited a higher success percentage with a high number of leaves per cutting and root length. But IBA 2500 ppm had also displayed the highest sprouting percentage, shoot length, number of shoots per cutting.

Cuttings planted between $15^{\text {th }}$ December to $15^{\text {th }}$ January through the quick dip method after treating with IBA, exhibit good sprouting. On the other hand, cuttings planted during January 25th showed the best survival and rooting parameters but with IBA 500 ppm. Weather conditions in spring offer a high possibility of rooting and survival of cuttings. Planting is usually done in spring (FebruaryMarch). But in subtropical regions planting in July and August (in the case of tropical regions), is ideal. 


\section{References}

Ansari, K. (2013). Effect of different collecting time and different medium on rooting of pomegranate "Malas torsh cv". Cuttings. Bulletin of Environmental Pharmacology and Life Science, 2(12), 164-168.

Chandra, R., \& Babu, K. D. (2010). Propagation of pomegranate: a review. Pomegranate. Fruit Veg. Cereal Sci. Biotechnol, 4, 51-55.

Deshmukh, S., Bharad, S. G., Deshmukh, P. L., \& Gholap, S. V. (2019). Effect of different media and time of cutting on rooting and growth of pomegranate cuttings. $P K V$ research journal, 43(1), 97-105.

Eed, A. M., Albana'a, B., \& Almaqtari, S. (2015). The effect of growing media and stem cutting type on rooting and growth of Bougainvillea spectabilis plants. Univ. Aden J. Nat. and Appl. Sc, 19(1), 141.

Food and Agricultural Organization of the United Nations, Cultivation of pomegranate A40 (2021).https://agricoop.nic.in/sites/default/f iles/2019-

20\%20\%281st\%20Adv.\%20Est.\%29\%284 $\% 29$-converted\%281\%29_0.pdf.

Frick, E. M., \& Strader, L. C. (2018). Roles for IBA-derived auxin in plant development. Journal of Experimental Botany, 69(2), 169-177.

Ghani, M., Sharma, M. K., \& Habibi, H. K. (2019). Effect of growing media on rhizogenesis and growth of rooted stem cuttings of pomegranate (Punica granatum) cv. Phule Bhagwa Super. Under Open Field Condition. Int. J. Curr. Microbiol. App. Sci, 8(7), 915-923.

Gurjar, P. K. S., \& Patel, R. M. (2007). Effect of rooting media type of stem cutting and growth regulator on rooting and growth of pomegranate cv. Ganesh. Bhartiya Krishi Anusandhan Patrika, 22(1), 62-66.

Hakim, A., Jaganath, S., Honnabyraiah, M. K., Kumar, S. M., Kumar, S. A., \& Dayamani, K. J. (2018). Effect of biofertilizers and auxin on total chlorophyll content of leaf and leaf area in pomegranate (Punica granatum L.) cuttings. International Journal of Pure and Applied Bioscience, 6(1), 987-991.

Hussain, I., Khattak, A. M., Amin, N. U., Aman, F., \& Sajid, M. (2012). Response of different pomegranate cuttings types to different environmental conditions. Sarhad journal of Agriculture, 28(1), 15-18.

Indian Production of Pomegranate(HSCODE1058), http://apeda.in/agriexchange/India\%20Prod uction/India_Productions.aspx?cat=fruit $\&$ h scode $=1058$.

Kabir, M. A., Prince, M. H., Karim, R., Rahman, S., Billah, K. M., \& Hasnat, G. T. (2017). Vegetative propagation of punica granatum by stem cuttings using non-mist propagator. International Journal of Agriculture System, 5(2), 185-197.

Kahramanoğlu, İ., \& Umar, K. (2018). Effects of cutting length, time and growing media on the sprouting of dormant semihardwood cuttings of pomegranate cv. Wonderful. African Journal of Agricultural Research, 13(45), 2587-2590.

Kamboj, S., Singh, K., Singh, S., \& Gandhi, N. (2017). Department of Agriculture, DAV College, Abohar (India). Effect of Indole Butyric Acid on Rooting and Vegetative Parameters of Pomegranate (Punica granatum L.) Cuttings. International journal of advance research in science, 6(01).

Kaur, S., Kaur, A., \& Kaur, G. (2016). Effect of IBA, PHB and time of planting on rooting of pomegranate (Punica granatum L.) cuttings cv. Ganesh. Asian Journal of Science and Technology, 7(11), 3757-3761.

Kaur, S., Kumar, D., Kumar, A., \& Yadav, J. K. (2018). Effect of IBA and PHB on roots and shoots of pomegranate (Punica granatum L.) cuttings cv. Ganesh. Journal of Pharmacognosy and Phytochemistry, 7(6), 1251-1254.

Koteswara Rao, G. S., Bisati, I. A., Sharma, A., Kosser, S., \& Bhat, S. A. (2020). Effect of IBA concentration and cultivars on number of leaves, leaf area and chlorophyll content of leaf in Pomegranate (Punica granatum 
L.) cuttings under temperate conditions of Kashmir. Journal of Pharmacognosy and Phytochemistry, 6, 86-90

Kumar, K., Tanuja, D. K., \& Naithani, D. C. (2017). Influence of different concentrations of IBA on the shooting and rooting of hardwood cuttings of pomegranate (Punica granatum L.) CV. ganesh under valley condition of Garhwal himalaya. Plant Archives, 17(1), 375-379.

Kumar, R., Meena, R., Sharma, B. D., \& Saroj, P. L. (2018). Production technology of pomegranate in arid regions. CIAH/Tech. Bull. (65), 5-6.

Kumar, S., Prakash, S., Prasad, Y., Kumar, A., Chand, P., \& Dhyani, B. P. (2020). Effect of IBA and boric acid treatments on rooting and growth of stem cutting in pomegranate (Punica granatum L.). Journal of Pharmacognosy and Phytochemistry, 9(5), 2714-2716.

Kumar, S., Prakash, S., Malik, S., \& Dhyani, B. P. (2021). Effect of different rooting media treatments on rooting and growth of stem cuttings in pomegranate (Punica granatum L.). The Pharma Innovation Journal; 10(3): 475-479.

Kumar, S., Prakash, S., Kumar, A., \& Dhyani, B. P. (2021). Effect of IBA, boric acid and wounding treatments on rooting and growth of stem cuttings in pomegranate (Punica granatum L.). The Pharma Innovation Journal; 10(3): 480-488.

Kumari, G. G. S., Kumari, S. A. S. M., Vithana, M. D. K., \& Mannanayake, M. A. D. K. (2013). Effect of plant growth regulators on hardwood cuttings of pomegranate (Punica granatum L.). In Proceedings of 12th Agricultural Research Symposium, 127-131.

Kumari K. R. (2014). Studies on the effect of IBA and rooting media on rhizogenesis of cuttings of pomegranate (Punica granatum L.) cv. Bhagwa under shade net conditions (Doctoral dissertation, Dr. YSR Horticulture University).

Lal, S., \& Ahmed, N. (2012). Standardization of rooting media for quality planting material Production of pomegranate (Punica granatum L.) under controlled atmosphere. Quality seeds and planting material in Horticultural crops, 268-277.

Manila, T., Rana, D. K., \& Naithani, D. C. (2017). Effect of different growing media on vegetative growth and rooting in pomegranate (Punica granatum L.) cv."Kandhari" hardwood stem cutting under mist. Plant Archives, 17(1), 391-394.

Mehta, S. K., Singh, K. K., \& Harsana, A. S. (2018). Effect of IBA concentration and time of planting on rooting in pomegranate (Punica granatum) cuttings. Journal of Medicinal Plants Studies, 6(1), 250-253.

Minaiyan, M., Zolfaghari, B., Taheri, D., \& Gomarian, M. (2014). Preventive effect of three pomegranate (Punica granatum L.) seeds fractions on cerulein-induced acute pancreatitis in mice. International journal of preventive medicine, 5(4), 394.

Netam, S. R., Sahu, G. D., Markam, P. S., \& Minz, A. P. (2020). Effect of different growing media on rooting and survival percentage of pomegranate (Punica granatum L.) cuttings $\mathrm{cv}$. super bhagwa under Chhattisgarh plains condition. International Journal of Chemical Studies: IJCS, 8(5), 1517-1519.

Pacurar, D. I., Perrone, I., \& Bellini, C. (2014). Auxin is a central player in the hormone cross talks that control adventitious rooting. Physiologia Plantarum, 151(1), 83-96.

Panda, C., \& Bhusan, L. P. (2016). Studies on propagation method of pomegranate (Punica granatum L.) by cuttings in costal climates of Odisha. Advances in Life Sciences, 5(21), 9801-9805.

Patel, K. D., Butani, A. M., Thummar, B. V., Purohit, H. P., \& Trambadiya, R. D. (2020). Response of different media and iba on rooting and survival percentage of hardwood cutting in pomegranate (Punica granatum L.) cv. Bhagwa. Journal of Pharmacognosy and Phytochemistry, 9(5), 322-329.

Pomegranate - National Horticulture Board (2020), http://nhb.gov.in/model-projectreports/Horticulture\%20Crops/Pomegranat 
e/Pomegranate1.htm.

Poudel, K., Sah, M. K., Mandal, J. L., \& Shrestha, J. (2018). Response of pomegranate to indole butyric acid concentration for rooting of stem cuttings. Nepalese Journal of Agricultural Sciences, 16, 84-88.

Rajkumar, J. S. G., Kumar, R., Singh, A., \& Kumar, A. (2016). Establishment, survival and growth of pomegranate cuttings with different concentrations of indole butyric acid and rooting substrates. Eco. Env. \& Cons, 22, 321-327.

Rathwa, A., Singh, V., Patel, A, D., \& Patel, A. (2017). Influence of Propagation Media on Growth of Hardwood and Semi-Hardwood Cuttings of Pomegranate cv. Bhagwa. Trend in Biosciences, 10(28), 6023-6027.

Seiar, Y. A. (2016). Effect of growth regulators on rooting of cuttings in pomegranate (Punica granatum L.) cv. 'Bhagwa'. Journal of Horticultural Sciences, 11(2), 156-160.

Singh, B., Singh, S., \& Singh, G. (2011). Influence of planting time and IBA on rooting and growth of pomegranate (Punica granatum L.) 'Ganesh' cuttings. Acta horticulturae, 890, 183-188.
Singh, K. K. (2014). Effect of IBA concentrations on the rooting of pomegranate (Punica granatum L.) cv. Ganesh hardwood cuttings under mist house condition. Plant Archives, 14(2), 1111-1114.

Singh, K. K. (2017). Vegetative propagation of pomegranate (Punica granatum L.) through cutting-A Review. International Journal of Current Microbiology and Applied Sciences, 6(10), 4887-4893.

Sonawane, M. S. (2017). Recent advances in the production of pomegranate fruit crop. Agriculture Update, 12(4), 657-665.

Tanwar, D. R., Bairwa, H. L., Lakhawat, S. S., Mahawer, L. N., Kumar Jat, R., \& Choudhary, R. C. (2020). Effect of IBA and rooting media on hardwood cuttings of pomegranate (Punica granatum L.) cv. Bhagwa. International Journal of Environment and Climate Change, 609617.

Taheri, M. N., Gholami, M., Baninasab, B., Mobli, M., \& Moradi, S. (2014). Pomegranate seed germination and dormancy breaking techniques. Seed Technology, 36(2), 139-149.

\section{How to cite this article:}

Avu. Durga, B. and Jatinder Singh. 2021. Response of Growing Media and IBA Application under Different Weather Conditions on Growth of Pomegranate (Punica granatum L.) Cuttings - A Review. Int.J.Curr.Microbiol.App.Sci. 10(11): 207-217. doi: https://doi.org/10.20546/ijcmas.2021.1011.024 